\title{
Anxiety related to sexual abuse: $A$ case of recurrent priapism
}

\author{
Allan Abbass, MD FRCPC; ${ }^{*}$ John Grantmyre MD, FRCSC; ${ }^{\dagger}$ Robin L. Kay, PhD ${ }^{\S}$
}

*Department of Surgery, Division of Urology, University of Ottawa, Ottawa, ON; †Professor and Deputy Chief of Urology, Department of Urology, Dalhousie University, Halifax, NS; §Assistant Clinical Professor, Department of Psychiatry and Biobehavioral Sciences, David Geffen School of Medicine at UCLA, Los Angeles, CA

Cite as: Can Urol Assoc J 2013;7:48-50. http://dx.doi.org/10.5489/cuaj.233

\section{Abstract}

Recurrent priapism is notoriously difficult to treat and very distressing to the sufferer. There is little literature about emotional contributors to this condition. We report a case of a man with sexual abuse and severe anxiety who responded acutely to emotion-focused treatment with persistent cessation of severe recurrent priapism episodes. A second case treated with the same method had a similar response to treatment. Emotional factors may be relevant in certain cases of recurrent priapism and these factors warrant clinical management and formal study.

\section{Background}

Sexual abuse can lead to a broad range of psychiatric and somatic problems which are direct manifestations of buried, intense and unacceptable emotions, including intense rage toward the perpetrator and guilt about the rage. These emotions can subsequently produce autonomic nervous system effects manifesting as striated muscle tension, smooth muscle tension and cognitive-perceptual disruption. ${ }^{1}$ Smooth muscle tension can produce hypertension, migraine, vasospasm and bladder spasm. These pathways can be directly diagnosed by emotion-focused interviewing ${ }^{1}$ and treated by specific emotion-focused treatments, including Intensive Short-term Dynamic Psychotherapy (ISTDP). ${ }^{2}$

Priapism is a vascular phenomena often triggered by or exacerbated by various medications. ${ }^{3}$ In a search of "priapism" and "sexual abuse" in PubMed (December 2011), there were no items found. Moreover, no references to sexual abuse or emotional factors as a causative agent were found in recent reviews of priapism treatment. ${ }^{3,4}$ In a single study linking anxiety and priapism, Burnett reported that 10 of 21 consecutive patients with idiopathic priapism had an anxiety disorder, suggesting that a "central neurobiological pathophysiological process" could be implicated. ${ }^{5}$

\section{Case report}

We report a case of recurrent priapism in a middle-aged man with a history of sexual abuse who responded to ISTDP treatment for trauma. This patient provided full consent for publishing his story to assist the treatment of others.

This patient is a 50-year-old homosexual man with recurrent priapism and a psychiatric history of severe depression and post-traumatic stress disorder. He was a heavy tobacco smoker, smoked marijuana and abused alcohol. Over the past 5 years, he was on at least 19 different psychotropic medications. ${ }^{3}$ At the start of this current treatment, he was taking methotrimeprazine $30 \mathrm{mg} /$ day, quetiapine $15 \mathrm{mg} /$ day, zopiclone 7.5-15 mg/day, diazepam $40 \mathrm{mg} /$ day, temazepam $15 \mathrm{mg}$ per day and gabapentin $600 \mathrm{mg} /$ day. Over the last 3 years of treatment, he was on and off varenicline for smoking cessation.

In addition to priapism, he also had Prinzmetal's angina with history of a myocardial infarction, hypertension, migraine and irritable bowel syndrome. So, he had many somatic problems related to autonomic nervous system dysfunction affecting smooth muscle tone in different body systems. He did not have sickle cell anemia or other hematological abnormality. He was on a calcium channel blocker (diltiazem) and occasionally required nitrospray. He had several physical, substance and medication-related risk factors for priapism.

He had a 7-year history of recurrent priapism. Over these years, he visited the emergency room 18 times, requiring drainage of the corpus cavernosa and irrigation with alpha adrenergic agents in 10 of these visits. When priapism was active, he suffered extreme agitation with suicidal ideation and thoughts of cutting off his own penis. He felt that stress made it more likely he would have a run of priapism episodes. It was felt that psychiatric medication had been causing his priapism episodes, but they were declared idiopathic.

ISTDP is an emotion-focused treatment that helps patients overcome self-destructive emotional and behavioural pat- 
terns that are rooted in emotional trauma. The treatment ranges from a few sessions up to a few years to treat severely personality disordered patients. It has been well-studied now with 25 outcome studies showing it be effective with a range of somatic conditions, including recurrent headache, "urethral syndrome"/pelvic pain ${ }^{7}$ and medically unexplained symptoms in emergency department patients. ${ }^{8}$ ISTDP is in a class of treatments called short-term psychodynamic psychotherapies; these therapies have demonstrated their effectiveness across a range of "physical" disorders and syndromes. ${ }^{9}$

After the first 2 years of weekly psychotherapy, he exhibited significant psychological and physical signs of improvement with reduced anxiety, depression, irritable bowel, angina episodes and migraine. He had markedly reduced alcohol use, ceased marijuana and returned to work 1 year into treatment. Priapism episodes, however, continued despite the fact that he reduced and stopped taking virtually all psychotropic medications, except clonazepam $0.5 \mathrm{mg}$ per day and zopiclone 7.5 to $15 \mathrm{mg}$ per day.

Due to the frequent recurrences of priapism, the patient was felt to have "stuttering priapism" and was started on sildenafil $25 \mathrm{mg}$ once a day. This approach to stuttering priapism has only recently been described. ${ }^{10}$ Trial of low dose sildenafil was felt to be helpful, but did not entirely stop his episodes. He continued to have an average of 6 episodes per month, but with less severe duration (usually 1 to 3 hours) and pain. He noted more frequent and severe episodes when he was more anxious.

One day he came to the office for his psychotherapy session with active priapism. He was very anxious and agitated. The focus was on the underlying feelings he had coming into the office that day and how he experienced those feelings. With this focus, he was able to identify and experience that he had massive rage within himself and an urge to grab and anally rape someone with the erection he had. When asked who he had in mind, he said the man who raped him at age 16. He began to experience the visceral activation of rage and as he did there was an abrupt cessation of all bodily anxiety. At that very moment the priapism acutely ceased. He was horrified at the fact that he had wanted to rape the man who had raped him. He felt terrible guilt about this. The result was a massive relief of anxiety in this session. In follow-up now over 4 years after the psychotherapy incident, he has had no significant priapism episodes and no emergency visits.

\section{Interpretation}

This is the case of a man with chronic anxiety and a trauma history who had an acute and persistent reduction of recurrent priapism concurrent with a specific psychotherapeutic process. Although this a medically complicated case with reducing risk factors (substance, medications) leading up to the time, the acute cessation in one session suggests that one contributor to priapism in this man's case was autonomic dysfunction due to anxiety mediated via the smooth muscle of the vasculature to the penis. ${ }^{3}$ It appears that when this anxiety was overcome by experiencing the underlying emotions, the autonomic system moderated, with changes in vascular tone and resultant acute cessation of the episode. These same phenomena are frequently seen in migraine patients ${ }^{1}$ in patients with irritable bowel syndrome ${ }^{10}$ and those with bladder spasm or urethral syndrome. ${ }^{7}$ All of these problems can respond to ISTDP and related therapies. ${ }^{11}$ Moreover, one of us also treated a similar case of a middleaged man with histories of both sexual abuse and recurrent priapism who had a cessation of episodes during treatment.

\section{Conclusion}

Our observations, in addition to Burnett's, suggest that good psychiatric and psychological care may reduce the frequency and severity of recurrent priapism, likely through combinations of autonomic changes and medication/substance reductions. Based on this concept, we propose that history-taking in these cases should include inquiry into anxiety and trauma histories as possible contributory factors to autonomic dysfunction. Finally, this treatment approach warrants formal study to determine whether underlying anxiety and trauma are present and whether this treatment can be effective in reducing recurrences in idiopathic priapism.

Competing interests: None declared.

This paper has been peer-reviewed.

\section{References}

1. Abbass A, Lovas D, Purdy A. Direct diagnosis and management of emotional factors in chronic headache patients. Cephalalgia 2008;28:1305-14. http://dx.doi.org/10.1111/i.1468-2982.2008.01680.x

2. Davanloo H. Intensive short-erm dynamic psychotherapy. Chichester, England: John Wiley \& Sons, 2000.

3. Broderick GA, Kadioglu A, Bivalacqua TJ, et al. Priapism: pathogenesis, epidemiology, and management. J Sex Med 2010;7(1 Pt 2):476-500. http://dx.doi.org/10.1111/i.1743-6109.2009.01625.x

4. Montague DK, Jarow J, Broderick GA, et al. American Urological Association guideline on the management of priapism. J Urol 2003;170(4 Pt 1):1318-24. http://dx.doi.org/10.1097/01. ju.0000087608.07371.ca

5. Burnett AL. Anxiety disorders in patients with idiopathic priapism: risk factor and pathophysiologic link? J Sex Med 2009;6:1712-8. http://dx.doi.org/10.1111/i.1743-6109.2009.01246.x

6. Davanloo H. Intensive Short-Term Dynamic Psychotherapy: Spectrum of Psychoneurotic Disorders. Int $J$ Short-Term Psychotherapy 1995;3:121-232.

7. Baldoni F, Baldaro B, Trombini G. Psychotherapeutic perspectives in urethral syndrome. Stress Med 1995;11:79-84. http://dx.doi.org/10.1002/smi.2460110115

8. Abbass A, Campbell S, Magee K, et al. Intensive short-term dynamic psychotherapy to reduce rates of emergency department return visits for patients with medically unexplained symptoms: preliminary evidence from a pre-post intervention study. CJEM 2009;11:529-34.

9. Abbass AA, Kisely S, Kroenke K. Short-term psychodynamic psychotherapies for somatic symptom disorders. Systematic review and meta-analysis. Psychother Psychosom 2009;78:265-74. http://dx.doi. org/10.1159/000228247 
Abbass et al.

10. Burnett AL, Bivalacqua $\mathrm{TJ}$, Champion $\mathrm{HC}$, et al. Feasibility of the use of phosphodiesterase type 5 inhibitors in a pharmacologic prevention program for recurrent priapism. J Sex Med 2006;3:1077-84. http:// dx.doi.org/10.1111/i.1743-6109.2006.00333.x

11. Creed F, Fernandes L, Guthrie E, et al.; North of England IBS Research Group. The cost-effectiveness of psychotherapy and paroxetine for severe irritable bowel syndrome. Gastroenterology 2003;124:303-17. http://dx.doi.org/10.1053/gast.2003.50055
Correspondence: Dr. Allan Abbass, Professor \& Director of Psychiatric Education Director, Centre for Emotions and Health Dalhousie University Rm 8203 - 5909 Veterans Memorial Lane Halifax NS, Canada B3H 2E2; fax: 902-473-4545; allan.abbass@dal.ca 